原著

\title{
GDCによる塞栓術導入後の脳動脈瘤の治療選択と成績
}

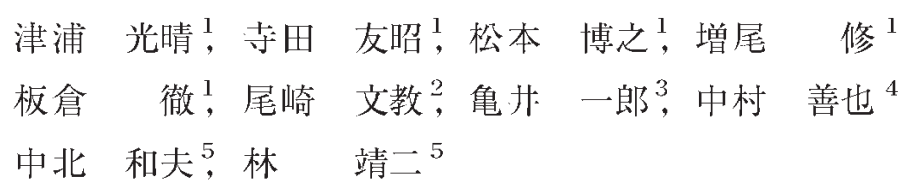

\section{Clinical Results and Selection of Treatment for Cerebral Aneurysms after Introduction of GDC Embolization}

\author{
Mitsuharu Tsuura, M.D., ${ }^{1}$ Tomoaki TeradA, M.D., ${ }^{1}$ Hiroyuki Matsumoto, M.D., ${ }^{1}$ \\ Osamu Masuo, M.D., ${ }^{1}$ Toru Itakura, M.D., ${ }^{1}$ Fuminori Ozaki, M.D., ${ }^{2}$ \\ Ichiro Kamei, M.D., ${ }^{3}$ Yoshinari Nakamura, M.D., ${ }^{4}$ Kazuo NakakitA, M.D., ${ }^{5}$ and \\ Seiji HaYASHI, M.D. ${ }^{5}$ \\ ${ }^{1}$ Department of Neurological Surgery, Wakayama Medical University, ${ }^{2}$ Department of \\ Neurological Surgery, Hidaka General Hospital, ${ }^{3}$ Department of Neurological Surgery, Japan \\ Red Cross Society Wakayama Medical Center, ${ }^{4}$ Department of Neurological Surgery, Wakayama \\ Rosai Hospital, and ${ }^{5}$ Department of Neurological Surgery, Minami-Wakayama National \\ Hospital, Wakayama, Japan
}

Summary: Recently, embolization using the Guglielmi detachable coil (GDC) has been performed as an alternative of direct surgery for cerebral aneurysms. We report clinical results and selection of treatment for cerebral aneurysms after introduction of GDC embolization at Wakayama Medical University and related hospitals. From 1997 to December 2001, 895 patients with intracranial aneurysms were treated either by direct surgery $(n=798)$ or by GDC embolization $(n=97)$. In 239 patients with unruptured aneurysms, 194 patients (81\%) underwent direct surgery, while 45 patients (19\%) had GDC embolization. In 656 patients with ruptured aneurysms, 604 cases (92\%) were treated by direct surgery and 12 cases (8\%), by GDC embolization. GDC embolization tended to be selected for paraclinoid IC or posterior fossa aneurysms, especially BA top, BA trunk and VA dissecting aneurysms. Vasospasm after SAH was statistically less in the embolization group than in the surgical group. In unruptured aneurysm series, morbidity and mortality rate of direct surgery was 5.7\% and $0.5 \%$, respectively, while those of GDC embolization was $4.4 \%$ and $0 \%$, respectively.

These clinical outcomes seemed to be almost the same as the previously published data by other neurosurgeons and interventional neuroradiologists. Therefore, our treatment selection and procedures are likely to be appropriate, especially in the unruptured group, after introduction of GDC embolization.

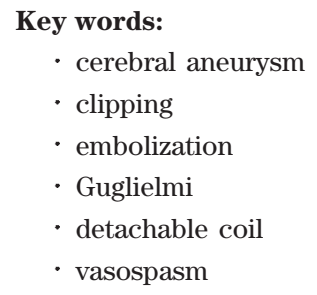

Surg Cereb Stroke

(Jpn) 31: 273-278, 2003

\footnotetext{
1 和歌山目立医科大学 䑈神経外科, ${ }^{2}$ 国保日高総合病院 脳神経外科, ${ }^{3}$ 日本赤十字社和歌山医療センター 脳神経外科, ${ }^{1}$ 和歌山労贸 病院脳神経外科, “国立南和歌山病院 脳神経外科(受稿日 2002.8.8)〔連絡先：テ646-8558 和歌山県田辺市たきない町27番 1号国 立南和歌山病院 脳神経外科 津浦光晴] [Mailing address: Mitsuharu TsuurA, M.D, Department of Neurological Surgery, MinamiWakayama National Hospital 27-1 Takinai-cho, Tanabe City, Wakayama 646-8558, Japan]
} 


\section{はじめに}

1997 年にGuglielmi detachable coil(GDC)がП本で脎動 脤治療に使用可能となってから 5 年にならうとするが,こ の間にGDCによる塞栓術の初期, 中期の治療成績が報告 され ${ }^{4) 22}, \mathrm{GDC}$ 塞栓術の適応も少しずっ変化していると 考えられる。また従来直澾手術の困難な動脈瘤の中にも GDC 塞栓術が安全で容易に施行できる症例があり，われ われの選択できる治療方針にも幅が広がったように思われ る.今回，われわれはGDC導人後脳動脈瘤の治療方針㧍 よび成績はどのようになっているか，単・施設だけでなく 和歌山県内の関連病院も含めた多施設で鬥査を行い検討し たので報告する。

\section{対象と方法}

対象はGDCの導人された1997年より2001年までに和 歌山県立医科大学脳神経外科㧍よびその主要関連病院の䏺 神経外科で治療が行われ当該施設より誠査咷の回答のあっ た 895 症例である。うち破裂動脤瘤が 656 例，未破裂動脤 瘤が 239 例で，798例に開頭手術，97例にGDCによる塞 栓術が施行された。GDC 塞栓術は原剘として全身麻酔下 に全身へパリン化を行い, 和歌山県立医科大学の血管内治 療チームが大学病院および関連施設で施行した。詰査豊の 回答項目としては治療法の選択と動脈瘤の部位, 未破裂動 䀼瘤については治療法の morbidity, mortality, complication, 術後 3 力月での outcome (modified Rankin disability scale: mRDS) があり, 破裂脳動脈瘤では術前の Hunt \& Kosnikのgrade と術後 3 力月での outcome (mRDS), vasospasm (術後 2 造間以内に施行したfollow-up の血管撮 影もしくは症状から vasospasmが疑われ施行した血管撮 影で vasospasmが認められたもの), 水頭症 (正常压水頭 症）の頻度について誠査した。

\section{結果}

\section{1. 治療法の選択}

未破裂脳動脈瘤 239 例中，開頭手術は194例 (81\%)に， GDC 塞栓術は45例 (19\%)に選択された。破裂脳動脈瘤で は 656 例中開頭手術は 604 例 $(92 \%)$, GDC 塞栓術は 52 例 (8\%)に選択された。緊急あるいは急性期手術の多い破裂 脳動脈瘤ではGDC 導人後も 9 割以上に開頭手術が選択さ れていた。

\section{2. 動脈瘤の部位と治療法の選択 (Table 1, 2)}

破裂脳動脈瘤では MCA, IC-ACh, distal ACAの動脈 瘤は全例開頭手術を選択されて抢り，逆にIC-Ophth， paraclinoid IC, BA trunk, BA top, VA dissecting
Table 1 Aneurysm location and treatment selection of cases of ruptured aneurysms

\begin{tabular}{|c|c|c|}
\hline & Surgery & Embolization \\
\hline MCA & $100 \% \quad(133)$ & $0 \%$ \\
\hline ICPC & $95 \% \quad(120)$ & $5 \%$ \\
\hline IC-ACh & $100 \% \quad(21)$ & $0 \%$ \\
\hline IC top & $88 \% \quad(7)$ & $12 \%$ \\
\hline AcomA & $96 \% \quad(138)$ & $4 \%$ \\
\hline distal ACA & $100 \% \quad(43)$ & $0 \%$ \\
\hline IC-Ophth, paraclinoid & $27 \%$ & $73 \%(11)$ \\
\hline BA top & $40 \%$ & $60 \% \quad(9)$ \\
\hline BA trunk & $50 \%$ & $50 \%$ \\
\hline BA-SCA & $67 \%$ & $33 \%$ \\
\hline VA-PICA & $60 \%$ & $40 \%$ \\
\hline VA dissecting & $14 \%$ & $86 \%$ \\
\hline
\end{tabular}

Table 2 Aneurysm location and treatment selection of cases of unruptured aneurysms

\begin{tabular}{|c|c|c|}
\hline & Surgery & Embolization \\
\hline MCA & $94 \% \quad(92)$ & $6 \%$ \\
\hline ICPC & $89 \% \quad(32)$ & $11 \%$ \\
\hline IC-ACh & $100 \%$ & $0 \% \quad|0|$ \\
\hline IC top & $56 \% \quad(5)$ & $44 \%$ \\
\hline AcomA & $90 \% \quad(27)$ & $10 \%$ \\
\hline distal ACA & $100 \% \quad(9)$ & $0 \% \quad(0)$ \\
\hline IC-Ophth, paraclinoid & $48 \% \quad(10)$ & $52 \%(11)$ \\
\hline BA top & $0 \% \quad(0)$ & $100 \%(10)$ \\
\hline BA trunk & ०\% & $100 \% \quad(1)$ \\
\hline BA-SCA & $60 \%$ & $40 \%$ \\
\hline VA-PICA & $67 \%$ & $33 \%$ \\
\hline VA dissecting & $50 \% \quad(1)$ & $50 \%$ \\
\hline
\end{tabular}

a neurysmに対しては $50 \%$ 以に塞栓術が選択されてい た。・般に頻度の高いICPC, AcomA， MCAの動脈瘤は $95 \%$ 以上が GDC 導人後も通常の開頭手術が選択されてい る。未破裂動脈瘤でも IC-ACh, distal ACAの動脈瘤では 全例に開頭手術が選択されたのに対し, BA top, BA trunkの動脈瘤には全例 GDC 塞栓術が選択されていた。

\section{3. 破裂脳動脈瘤の術前 Hunt \& Kosnik grade と 3 力月後 の outcome(mRDS)について (Table 3,4)}

破裂脳動脈瘤の outcomeは術前の gradeに大きく影響 されることはいうまでもないが, vasospasmの有無など によっても左右される。開頭手術例, 塞栓術例の outcome を Table 3,4 にそれぞれ示す。当然予想されることである が, ともに術前の Hunt \& Kosnik grade 3 以下はmRSの 0-3の症例が多いが, grade 4 以上になると $\operatorname{mRS} 0-3$ が 減って4-6が多い傾向がある。 
Table 3 Relationship between preoperative Hunt \& Kosnik grade and outcome (modified Rankin disability scale at 3 months) in cases of direct surgery for ruptured aneurysms

\begin{tabular}{|c|c|c|c|c|c|c|c|c|c|}
\hline \multirow{2}{*}{\multicolumn{2}{|c|}{ Surgery }} & \multicolumn{7}{|c|}{$m R S$} & \\
\hline & & 0 & 1 & 2 & 3 & 4 & 5 & 6 & \\
\hline \multirow{6}{*}{$H \& K$ grade } & 1 & 30 & 5 & 5 & 8 & 3 & 1 & 1 & 53 \\
\hline & 2 & 72 & 26 & 11 & 13 & 6 & 7 & 8 & 143 \\
\hline & 3 & 29 & 10 & 9 & 9 & 22 & 22 & 14 & 115 \\
\hline & 4 & 9 & 7 & 8 & 9 & 19 & 24 & 24 & 100 \\
\hline & 5 & 0 & 0 & 0 & 3 & 3 & 3 & 4 & 13 \\
\hline & & 140 & 48 & 33 & 42 & 53 & 57 & 51 & 424 \\
\hline
\end{tabular}

Table 4 Relationship between preoperative Hunt \& Kosnik grade and outcome (modified Rankin disability scale at 3 months) in cases of GDC embolization for ruptured aneurysms

\begin{tabular}{cc|ccccccc|c}
\hline \multirow{2}{*}{ Embolization } & \multicolumn{7}{|c}{ mRS } & & \\
\hline \multirow{3}{*}{ H\& K grade } & 1 & 7 & 1 & 0 & 1 & 0 & 0 & 0 & 9 \\
& 2 & 5 & 4 & 3 & 3 & 2 & 0 & 2 & 19 \\
& 3 & 2 & 0 & 0 & 3 & 0 & 3 & 0 & 8 \\
& 4 & 0 & 2 & 0 & 2 & 3 & 6 & 1 & 14 \\
& 5 & 0 & 0 & 0 & 0 & 1 & 2 & 2 & 5 \\
\hline & 14 & 7 & 3 & 9 & 6 & 11 & 5 & 55 \\
\hline
\end{tabular}

\section{4. 破裂動脈瘤症例での vasospasm と水頭症 (normal pressure hydrocephalus: NPH) の頻度}

vasospasm (術後 2 遇間以内に施行した follow-upの血管 撮影もしくは症状から vasospasmが疑われ施行した血管 撮影で vasospasmが認められたもの)は開頭手術例 439 例 中 $43.5 \%$ に発生したのに対し, 塞栓術例では 48 例中 10 例, $20.8 \%$ に生じた。一方，水頭症 (NPH) に関しては開頭手術 例 433 例中 136 例， $31.6 \%$ に生じたのに対し，塞栓術例で は 93 例中 23 例， $23.7 \%$ にのみ生じた。開頭手術と塞栓術 で vasospasm, NPHの頻度に差があるか Fisher's exact probability testで検定すると, vasospasmに関しては $\mathrm{p}=$ $0.003<0.05$ で有意差があるが, NPHに関しては $\mathrm{p}=$ 0.216>0.05で有意差が認められなかった。

\section{5. 未破裂脳動脈瘤症例の術前 $\mathrm{mRDS}$ と 3 カ月後の $\mathrm{mRDS}$ について (Table 5, 6)}

当然ながら未破裂脳動脈瘤症例の術前の mRDSは 0-1 と良好なものが多く，術後にmRDSの低下しているもの は合併症などで神経脱落症状が出現した症例が多いと考元 られる。術前より術後にmRDSが低下していた症例は， 開頭手術では 16\%(13/194)，塞栓術では20\%(9/45)に認 められたが，術前mRDSが0から術後 1 に低下したものが 大部分であった。
Table 5 Relationship between preoperative modified Rankin disability scale and outcome (modified Rankin disability scale at 3 months) in cases of direct surgery for unruptured aneurysms

\begin{tabular}{lc|ccccccc|c}
\hline \multicolumn{2}{c|}{ Surgery } & 0 & 1 & 2 & 3 & 4 & 5 & 6 & \\
\hline preoperative & 0 & 119 & 12 & 6 & 4 & 1 & 0 & 0 & 142 \\
mRS & 1 & 2 & 19 & 3 & 1 & 1 & 0 & 0 & 26 \\
& 2 & 0 & 0 & 6 & 1 & 0 & 0 & 0 & 7 \\
& 3 & 0 & 0 & 1 & 4 & 1 & 0 & 0 & 6 \\
& 4 & 0 & 0 & 0 & 1 & 0 & 1 & 0 & 2 \\
& 5 & 0 & 0 & 0 & 0 & 1 & 1 & 0 & 2 \\
\hline & 121 & 31 & 16 & 11 & 4 & 2 & 0 & 185 \\
\hline
\end{tabular}

Table 6 Relationship between preoperative modified Rankin disability scale and outcome (modified Rankin disability scale at 3 months) in cases of GDC embolization for unruptured aneurysms

\begin{tabular}{ll|ccccccc|c}
\hline \multicolumn{2}{l|}{ Embolization } & 0 & 1 & 2 & 3 & 4 & 5 & 6 & \\
\hline preoperative & 0 & 23 & 4 & 0 & 0 & 1 & 1 & 0 & 29 \\
mRS & 1 & 2 & 6 & 1 & 0 & 0 & 0 & 1 & 10 \\
& 2 & 1 & 0 & 1 & 0 & 0 & 0 & 0 & 2 \\
& 3 & 0 & 0 & 0 & 1 & 0 & 0 & 0 & 1 \\
& 4 & 0 & 0 & 0 & 0 & 1 & 0 & 0 & 1 \\
& 5 & 0 & 0 & 0 & 0 & 0 & 0 & 0 & 0 \\
\hline & 26 & 10 & 2 & 1 & 2 & 1 & 1 & 43 \\
\hline
\end{tabular}

\section{6. 未破裂脳動脈瘤症例の手技に関連した morbidity, mortality}

われわれの関連施設での開頭手術，塞栓術に関連した morbidity, mortalityは開頭手術の morbidityが $5.7 \%$ (11/194), 塞栓術が $4.4 \%(2 / 45)$, 開頭手術の mortalityが 0.5\%(1/194)，塞栓術の mortality が $0 \%(0 / 45)$ であった。

\section{7. 未破裂脳動脈瘤症例の開頭手術の手技に関連した合併 症 (Table 7)}

Table に示すように194例中 14 例に合併症が認められ， うち 11例(Case 1-11)が症候性で morbidityの原因となっ た。開頭手術の合併症の原因としては動脈瘤近傍の穿通枝 や分枝の閉塞, 周囲の脳神経損傷, 静脈性棟塞が主なもの であった。

\section{8. 未破裂脳動脈瘤症例の塞栓術の手技に関連した合併症 (Table 8)}

塞栓術の手技に起因する合併症は 45 例中 4 例あり，う ち 2 例 (Case 15-16) が神経脱落症状を残し morbidityの原 因となった。内䚿は動脈瘤近傍の分枝の閉塞 1 例，末梢塞 栓 1 例, 動脤瘤の穿孔による出血 1 例，皮下血腫 1 例であ 
Table 7 Summary of complications direct surgery for unruptured aneurysms

\begin{tabular}{cllll}
\hline Case & Location & \multicolumn{1}{c}{ Complication } & \multicolumn{1}{c}{ Cause } & Outcome (mRDS) \\
\hline $1^{*}$ & MCA & hemiparesis & infarct (perforator occl.) & 3 \\
$2^{*}$ & MCA & visual loss & CRAO (?) & 1 \\
$3^{*}$ & MCA & motor aphasia & - & 2 \\
$4^{*}$ & MCA & hemiparesis & venous infarct & 2 \\
$5^{*}$ & MCA & hemiparesis & - & 3 \\
$6^{*}$ & AcomA & visual disturbance & - & 1 \\
$7^{*}$ & AcomA & Korsakoff's synd. & perforator occl. & 3 \\
$8^{*}$ & AcomA & dementia & postoperative bleeding & 1 \\
$9 *$ & IC paraclinoid & visual disturbance & optic n injury & 1 \\
$10^{*}$ & BA-SCA, IC-ACh & subcortical hematoma, & 3rd n palsy & 1 \\
$11^{*}$ & VA-PICA & cranial n. injury & & 4 \\
12 & ICPC & - & venous infarct & 1 \\
13 & AcomA & - & venous infarct & 1 \\
14 & MCA & aphasia & vasospasm & 0 \\
\hline
\end{tabular}

* permanent neurological deficits, CRAO: central retinal artery occlusion

Table 8 Summary of complications of GDC embolization for unruptured aneurysms

\begin{tabular}{clllc}
\hline Case & Location & \multicolumn{1}{c}{ Complication } & \multicolumn{1}{c}{ Cause } & Outcome (mRDS) \\
\hline $15^{*}$ & AcomA & hemiparesis & infarct due to ACA occlusion & 4 \\
$16^{*}$ & IC top & hemiparesis, aphasia & infarct due to embolism & 1 \\
17 & MCA & dementia (NPH) & SAH due to perforation & 1 \\
18 & BA top & numbness of upper limb & subcutaneous hematoma & 1 \\
\hline
\end{tabular}

* permanent neurological deficits

った。

\section{考察}

今回のわれわれの誠査より和歌山県立医科大学の主要関 連施設では，GDC 塞栓術導人後も破裂脳動脈瘤の $92 \%$, 未破裂脳動脈瘤の $81 \%$ に開頭手術が選択されていること がわかった。従来より・般的に手術が行われている MCA, ICPC, AcomA の動脈瘤に関しては $95 \%$ 以上が開頭手術 を選択されて招り，GDC 塞栓術は従来開頭手術が困難と 考えられる部位, BA top, BA trunkなどの動脈瘤に主に 選択されていた。これはいまたに開頭手術が gold standard であり，GDC 塞栓術の完全閉塞率が clippingよりも 低く coil compactionなどにより再開通の可能性が高いと いう認識があるため ${ }^{5}$, 開頭手術の比較的容易な動脈瘤は clippingを行う傾向があると考えられる

また今回の破裂脳動脈瘤症例の検討では術後の vasospasm (症候性, 無症候性を含む) は開頭手術よりも塞 栓術で起こりにくいと考えられた。これは塞栓術のほうが 直接血管の外表面を刺激して mechanical spasmを起こす 可能性が低いこと, 虚血を患化させる周囲脳組織への圧迫 がないこと, 正常の脳脊髄液の流通経路をくも膜の切開な
どで変化させることが少ないため血腫や㲗縮誘起物質が洗 い流されやすい，などの理由が考えられる。これに対して 開頭手術ではくも膜下腔に人り込んだ血腫を直視下で除去 できる利点があるが，逆にこの操作が vasospasmを誘発 したり虚血を患化させる可能性も考えられる6 16). 明確な 理由は不明であるが，问様に塞栓術のほうがvasospasm を起こしにくいという報告がされており今後の多症例数で の検討が待たれる る は術後 vasospasmの起こる時期に・致して神経学的患化 を示す他の合併症（髄膜炎など）が起こりこれも今回の vasospasmに含まれている可能性がある。

水頭症に関しては今回の調査では開頭手術と塞栓術で発 生頻度に統計学的有意差がなかったが, 塞栓術ではくも膜 の損傷，切開がないため生理的な髄液循環路に沿った血腫 の洗い流しが期待されNPHを含めた水頭症が起こりにく い可能性が考えられる。

また未破裂脳動脈瘤については手技に関連したmorbidity, mortalityがそれぞれ開頭手術では $5.7 \% ， 0.5 \%$ ，塞栓術 では 4.4\%，0\%という成績であり，従来より開頭手術が困 難で morbidity, mortalityの高いと考えられる BA top, BA trunk, VA dissecting aneurysm, paraclinoid IC 
aneurysmの多くが塞栓術を選択されていることから， GDC 尊人後の治療成績は良好と考えられる。他の未破裂 脳動脈瘤の治療成績と比較してみると, 開頭手術では morbidity, mortality が, Samson (1997)が 6.3\%, 0\%, Wirth (1987)が mobidity $7 \%$, King (1994)が mortality $1 \%$, Solomon(1998)がそれぞれ 7\%, 3.5\%, Raaymaker (1998) が 10.9\%，2.6\%, Wardlaw (2000) が10.9\%，3.8\% と報告し て扔り，われわれの成績もほぼ同等の数值と考えられる 17) 20)21)23) 24) 。塞栓術に関してはBristla (1999) が mor bi dity $3.7 \%$, Wardlaw $(2000)$ が morbidity $4 \%$, mortality $1 \%$, Johnston (2001) が morbi dity $10 \%$, mortality $0.5 \%$ を報告 しており，これもほほ同等の遜色ない成績と考えられる2〉 8) 23)

われわれの㑉査では morbidity, mortalityの原因となっ た合併症の内䚿は，未破裂動脈瘤の開頭手術については (1)動脈瘤近傍の穿通枝, 分枝の閉塞, (2) 周囲の脳神経 の損傷，(3)静脈性検塞，(4)術後出血が主な原因となっ ていた、GDCを用いた塞栓術では (1) 動脈瘤近傍の分枝の 閉塞，(2) 末梢塞栓，(3) 動脈瘤の穿孔，(4)皮下血腫が主 な原因と考えられた。今後はこれらの検討結果を踏まえ て, 特に頻度の高い重篤な合併症の術前予測とそれに基づ いた適応の決定, 治療の際の予防策の参考にすべきと考え ている。

今回の調査対象では塞栓術に関しては和歌山県立医科大 学の血管内治療グループがほほ共通して行っているが, 開 頭手術については各施設で成績に差がある可能性が考えら れる.しかし単・施設での少数症例での検討よりも和歌山 県全体での脳動脈瘤の治療成績の傾向を知り, 寸でに報告 されている諸家の成績と比較し反省点を検討する目的であ えて多施設全体でまとめて評価した。またoutcomeは3カ 月後の modified Rankin disability scale としたが, 報告に よっては治療成績を 6 力月後の outcomeで評価しているも のも多く，今後は6力月後あるいはより長期の outcomeの 検討も必要と思われる。従来よりいわれているょうに GDC 塞栓術は morbidity, mortality は良好なものの clippingよりも動脈瘤の完全閉塞率が低く再開通の頻度も高 いことから ${ }^{5 / 10\rangle}$, 今回は検討していないが, 今後は閉塞率 の結果も含めて outcomeを評価する必要があると思われ る。また今回は調査の煩雑さを避けるため刘象となった施 設で GDC 塞栓術導人以前の 動脈瘤の治療成績と尊人後の 治療成績を比較して㧍らず，今後はこの比較検討を行いた い.

今回の結果より GDC 塞栓術導人後のわれわれの脳動脈 瘤の治療成績は, 特に未破裂動脈瘤に扔いては諸家の成績 とほぼ同じであり適切なものと考えている，開頭手術によ る clipping は動脈瘤治療の gold standardで確立されてい
ると同時に,ここ数年は epoch-making な変化は認められ ないように思われる。一方, 塞栓術の技術的進歩はめざま しく現在も塞栓率を上げ観察期間中の再開通を減少させる べく,さまざまな新しい coil や澒部の広い動脈瘤に対して 塞栓術を容易にする device や technique が開発されている 3) 11) 13) 15)18).これらの進歩により将来コイル塞栓術の適 応は今以上に拡大し, 成績はさらに向上すると推察される。 進歩の著しい塞栓術という alternative 老開頭手術にうま く組み合わせることにより良好な治療成績も報告されつつ あ $り^{12)}$, 和歌山県全体での脳動脈瘤の治療成績がさらに 改善することが期待される。

\section{結＼cjkstart語}

われわれの関連施設での GDC 塞栓術導人後の脳動脈瘠 に対する治療成績は，未破裂脳動脈瘤に㧍いては開頭手術 が morbidity $5.7 \%$, mortality $0.5 \%$, 塞栓術が morbidity 4.4\%, mortality $0 \%$ と過去の報告と比較してまずまず良 好であった、GDCの導人により開頭手術が困難で塞栓術 が比較的容易と考元られる症例はGDC 塞栓術にまわって 扔り，両治療法がうまく選択されている可能性が考えられ る。GDC塞栓術は長期の follow-upによる再開通の問題な ど改良すべき点が多々あるが，脳動脈治療の成績を良好に している重要な治療選択枝と考元られる。

\section{文献}

1) Bavinzski G, Killer M, Gruber M, et al: Treatment of basilar artery bifurcation aneurysms by using Guglielmi detachable coils: a 6-year experience. J Neurosurg 90: 843-852, 1999

2) Brilstla EH, Rinkel GJ, van der Graaf Y, et al: Treatment of intracranial aneurysms by embolization with coils: a systematic review. Stroke 30: 470-476, 1999

3) Cloft HJ, Joseph GJ, Tong FC, et al: Use of three-dimensional Guglielmi detachable coils in the treatment of widenecked cerebral aneurysm. Am J Neuroradiol 21: 1312-1314, 2000

4) Cognard C, Weill A, Spelle L, et al: Long-term angiographic follow-up of 169 intracranial berry aneurysms occluded with detachable coils. Radiology 212: 348-356, 1999

5) Gruber DP, Zimmermen GA, Tomsick TA, et al: A comparison between endovascular and surgical management of basilar artery apex aneurysms J Neurosurg 90: 868-874, 1999

6) Gruber A, Ungersbock K, Reinprecht A, et al: Evaluation of cerebral vasospasm after early surgical and endovascular treatment of ruptured intracranial aneurysms. Neurosurgery 42: 258-268, 1998

7) Hohlrieder M, Spiegel M, Hinterhoelzl J, et al: Cerebral vasospasm and ischaemic infarction in clipped and coiled intracranial aneurysm patients Eur J Neurol 9(4): 389-399, 2002

8) Johnston SC, Zhao S, Dudley A, et al: Treatment of unruptured cerebral aneurysms in California. Stroke 32: 597-605, 2001 
9) King JT Jr, Berlin JA, Flamm ES, et al: Morbidity and mortality from elective surgery for asymptomatic, unruptured, intracranial aneurysms: a meta-analy sis. J Neurosurg 81: 837-842, 1994

10) Koivisto $\mathrm{T}$, Vanninen R, Hurskainen H, et al: Outcomes of early endovascular versus surgical treatment of ruptured cerebral aneurysms A prospective randomized study. Stroke 31: 2369-2377, 2000

11) Lanzino G, Wakh loo A K, Fessler RD, et $a l$ : Efficacy and current limitations of intravascular stents for intracranial internal carotid, vertebral, and basilar artery aneurysms. J Neurosurg 91: 538-546, 1999

12) Lot G, Houdart E, Cophignon J, et al: Combined management of intracranial aneurysms by surgical and endovascular treatment. Modalities and results from a series of 395 cases. Acta Neurochir (Wien) 141: 557-562, 1999

13) Moret J, Cognard C, Weill A, et al: The "remodelling technique" in the treatment of wide neck intracranial aneurysms Intervent Neuroradiol 3: 21-35, 1997

14) Murayama $Y$, Malisch T, Guglielmi G, et al: Incidence of cerebral vasospasm after endovascular treament of acutely ruptured aneurysms: report on 69 cases J Neurosurg 87: 830-835, 1997

15) Murayama $Y$, Vinuela F, Tateshima $T$, et al: Cellular responses of bioabsorbable polymeric material and Guglielmi detachable coil in experimental aneurysms. Stroke 33: 1120-1128, 2002

16) Oehman J, Servo A, Heiskanen G, et al: Risks factors for cerebral infarction in good-grade patients after aneurys- mal subarachnoid hemorrhage and surgery: a prospective study. J Neurosurg 74: 14-20, 1991

17) Raaymakers TWM, Rinkel GJE, Limburg M, et al: Mortality and morbidity of surgery for unruptured intracranial aneurysms. A mete-analysis. Stroke 29: 1531-1538, 1998

18) Raymond J, Guilbert F, Roy D, et al: Neck-bridge device for endovascular treatment of wide-neck bifurcation aneurysms initial experience. Radiology 221: 318-326, 2001

19) Regli L, Uske A, de Tribolet N: Endovascular coil placement compared with surgical clipping for the treatment of unruptured middle cerebral artery aneurysms a consecutive series. J Neurosurg 90: 1025-1030, 1999

20) Samson DS, Hodosh RM, Clark WK: Surgical management of unruptured asymptomatic aneurysms. J Neurosurg 46: 731-734, 1977

21) Solomon RA, Fink ME, Pile-Spellman J: Surgical management of unruptured intracranial aneurysms $J$ Neurosurg 80: 440-446, 1994

22) Vinuela F, Duckwiler G, Mawad M: Guglielmi detachable coil embolization of acute intracranial aneurysm: perioperative anatomical and clinical outcome in 403 patients. $J$ Neurosurg 86: 475-482, 1997

23) Wardlaw JM, White PM: The detection and management of unruptured intracranial aneurysms. Brain 123: 205-221, 2000

24) Wirth FP, Laws ER Jr, Piepgas D, et al: Surgical treatment of incidental intracranial an eurysms. Neurosurgery 12: $507-511,1983$ 